\title{
Differential effect of statin use on coagulation markers: an active comparative analysis in the NEO study
}

\author{
Mohammadreza Bordbar ${ }^{1}$ (D), Renée de Mutsert ${ }^{2}$, Melike Cevval ${ }^{2}$, Frits R. Rosendaal ${ }^{2}$, J. Wouter Jukema ${ }^{3}$ and \\ Willem M. Lijfering ${ }^{2 *}$
}

\begin{abstract}
Background: Statins are a potential treatment for venous thromboembolism (VTE) prophylaxis complementary to conventional anticoagulants without associated bleeding complications. This study aimed to compare prothrombotic activities of different classes of lipid-lowering drugs in an active comparator design and determine whether there is a relation between statin versus fibrate/niacin use and pro-coagulant factor outcomes.

Methods: This is a cross-sectional analysis of participants from the Netherlands Epidemiology of Obesity study using any class of lipid-lowering drugs, including any types of statins, niacin, and fibrates. We performed linear regression analyses to determine fibrinogen, factor (F) VIII, FIX, and FXI activity in statins versus fibrate/niacin users and adjusted for age, sex, tobacco smoking, body mass index (BMI), hypertension, diabetes, and prevalent cardiovascular disease.

Results: Among 1043 participants, the mean age was $58.4 \pm 5.2$ years, 61\% were men, and the mean BMl was $31.3 \pm 4.5 \mathrm{~kg} / \mathrm{m}^{2}$. Clinical characteristics were balanced between statin and fibrate/niacin users. Statin users had lower mean FXI (18.3 IU/dL, 95\% confidence interval (Cl) 9.4 to 27.3$)$ levels compared to fibrate/niacin users. The level of FVIII $(15.8 \mathrm{IU} / \mathrm{dL}, 95 \% \mathrm{Cl}-0.003$ to 31.6$)$, and $\mathrm{FIX}(11.3 \mathrm{IU} / \mathrm{dL}, 95 \% \mathrm{Cl}-0.4$ to 23.2) were lower in statin users than fibrate/niacin users with marginal statistical significance.

Conclusion: Current statin use was associated with lower plasma levels of FXI than fibrate/niacin use. The effects on coagulation factors may, in part, explain the benefit of statin therapy rendered in primary and secondary prevention of VTE.
\end{abstract}

Keywords: Statins, Venous thromboembolism, Coagulation factors, Niacin, Fibrates

\section{Introduction}

Venous thromboembolism (VTE) has an estimated annual incidence rate of 1-2 per 1000 person-years among people of European ancestry [1]. The 3-hydroxy-3-methylglutaryl-coenzyme A (HMG-CoA) reductase inhibitors, the so-

\footnotetext{
* Correspondence: w.m.lijfering@lumc.nl

${ }^{2}$ Department of Clinical Epidemiology, Leiden University Medical Center, Albinusdreef 2, 2333, ZA, Leiden, The Netherlands

Full list of author information is available at the end of the article
}

called statins, are a class of lipid-lowering drugs widely used to prevent arterial atherosclerotic disease [2].

A growing body of evidence indicates that statins are a promising treatment for VTE prophylaxis complementary to anticoagulants without associated bleeding complications [3-9].

Statins have anti-inflammatory and anti-oxidant properties besides their lipid-lowering effects $[10,11]$. Moreover, it has been postulated by mainly in-vitro studies and observational studies that they may have beneficial

C C The Author(s). 2021 Open Access This article is licensed under a Creative Commons Attribution 4.0 International License, which permits use, sharing, adaptation, distribution and reproduction in any medium or format, as long as you give appropriate credit to the original author(s) and the source, provide a link to the Creative Commons licence, and indicate if changes were made. The images or other third party material in this article are included in the article's Creative Commons licence, unless indicated otherwise in a credit line to the material. If material is not included in the article's Creative Commons licence and your intended use is not permitted by statutory regulation or exceeds the permitted use, you will need to obtain permission directly from the copyright holder. To view a copy of this licence, visit http://creativecommons.org/licenses/by/4.0/ The Creative Commons Public Domain Dedication waiver (http://creativecommons.org/publicdomain/zero/1.0/) applies to the data made available in this article, unless otherwise stated in a credit line to the data. 
effects on the vessel wall and anti-thrombotic properties $[12,13]$. These include decreased tissue factor expression and thrombin generation, impairment of procoagulant reactions catalyzed by thrombin including fibrinogen cleavage and factor (F) V and FXIII activation, reduction of FVII and FVIII activity, enhanced endothelial thrombomodulin expression, and upregulation of fibrinolytic activity manifested by decreased plasminogen activator inhibitor (PAI)-1 and increased tissue plasminogen activator (tPA) expression $[14,15]$. In addition, it has also been postulated to have antiplatelet effects by immediate and delayed inhibition of platelet activation, adhesion, and aggregation, although a previous trial could not confirm these findings in vitro $[15,16]$.

A randomized trial recently showed that 1 month of treatment with rosuvastatin $20 \mathrm{mg} /$ day leads to an improved coagulation profile, most notably decreased FVIII, in patients with prior VTE compared to nonstatin users [17]. Given that the effects of drugs are not necessarily class effects, the reduction of pro-coagulant factors by rosuvastatin may not be generalized to other statins currently on the market. It is known that different types of statins show different reducing effects on low-density lipoprotein, atherosclerosis, and inflammation. This reduction is the least strong in pravastatin users, followed by simvastatin and atorvastatin users, and is strongest in rosuvastatin users [16, 18, 19]. A meta-analysis of randomized clinical trials suggested a dose-response relation where rosuvastatin, which is most related to halting or regression of atherosclerosis, dyslipidemia, and inflammation, also provided the most substantial risk reduction in the occurrence of venous thrombosis [20].

We aimed to examine whether there is a relation between statin use and pro-coagulant factor outcomes in individuals participating in the Netherlands Epidemiology of Obesity (NEO) study [21].

\section{Materials and methods}

We performed a cross-sectional analysis of baseline measurements of participants from the NEO study who used a class-specific lipid-lowering drug (statin or fibrate/niacin) and compared their pro-thrombotic activities in an active comparator design.

The NEO study is a cohort study in 6671 individuals aged 45-65 years living in the Leiden area (West of the Netherlands). The majority of the participants have a selfreported body mass index (BMI) of $27 \mathrm{~kg} / \mathrm{m}^{2}$ or higher. At the baseline visit, blood samples were drawn into tubes containing $0.106 \mathrm{M}$ trisodium citrate (Sarstedt, Numbrecht, Germany) after an overnight fast. Plasma was obtained by centrifugation at $2500 \times \mathrm{g}$ for $10 \mathrm{~min}$ at room temperature and stored in aliquots at $-80^{\circ} \mathrm{C}$ until testing. Fibrinogen activity was measured according to the method of Clauss.
In addition, the activity of FVIII:C, FIX:C, FXI:C, was measured with a mechanical clot detection method on an ACL TOP 700 analyzer (Werfen, Barcelona, Spain). All assays were performed by laboratory technicians who were unaware of the status of the samples.

Since comparisons between statin-users and nonstatin users are likely to be confounded, we selected participants who were using any class of lipid-lowering drugs (self-reported), including statins, niacin, and fibrates. The European Society of Cardiology (ESC) and the European Atherosclerosis Society (EAS) guidelines for the management of dyslipidemias recommend that statins are always tried first, and niacin/fibrates are prescribed when statins are not tolerated [22], making niacin/fibrates a better comparator since side effects from statins are expected to be random. In total, 1043 cases were included in the active comparator analysis.

\section{Statistical analysis}

The participants' general characteristics were reported as means ( \pm standard deviation) or numbers (with percentages). As niacin/fibrates are not associated with antithrombotic properties [23], participants who used this class of drugs were regarded as the reference group. The mean of coagulation factors in participants using any statins were compared with the reference group using linear regression and reported as mean difference. The effect size was shown with $95 \%$ confidence intervals (CI).

One assumption is that there is no preference in prescribing a lipid-lowering drug to a specific patient and that the clinical characteristics should be distributed evenly over the participants. Given that this assumption might be too strong, we included age, sex, tobacco smoking, BMI, hypertension, diabetes, and prevalent cardiovascular disease (myocardial infarction, angina pectoris, congestive heart failure) as potential confounding factors to the regression analyses. All statistical analyses were computed in SPSS version 22.0.

\section{Results}

The general characteristics of participants $(n=1043)$ who used lipid-lowering medication at baseline are shown in Table 1 . The majority of them used five different classes of statins. A small subgroup $(n=22)$ used niacin/fibrates as the lipid-lowering drug. More than two-thirds of the participants reported to smoke (past or current), and nearly half of them were hypertensive (systolic blood pressure (BP) $\geq 140 \mathrm{mmHg}$ and/or diastolic $\mathrm{BP} \geq 90 \mathrm{mmHg}$ ). About one-third of the patients were diabetic (self-reported diabetes mellitus on medication or fasting plasma glucose $>7 \mathrm{mmol} / \mathrm{L}$ ) or had impaired fasting glucose $(6.1-7 \mathrm{mmol} / \mathrm{L})$.

The crude analysis revealed that all coagulation factors were lower in statin users than in fibrate/niacin users 
Table 1 General characteristics of the study population

\begin{tabular}{|c|c|c|c|c|c|c|}
\hline General characteristics & $\begin{array}{l}\text { Fibrate /Niacin } \\
(n=22)\end{array}$ & $\begin{array}{l}\text { Fluvastatin } \\
(n=10)\end{array}$ & Pravastatin $(n=114)$ & $\begin{array}{l}\text { Simvastatin } \pm \text { Ezetimab } \\
(n=612)\end{array}$ & $\begin{array}{l}\text { Atorvastatin } \\
(n=181)\end{array}$ & $\begin{array}{l}\text { Rosuvastatin } \\
(n=104)\end{array}$ \\
\hline Mean age, $Y(S D)$ & $57.5 \pm 4.7$ & $62.3 \pm 5.5$ & $58.1 \pm 5.2$ & $58.3 \pm 5.2$ & $59.0 \pm 4.6$ & $57.7 \pm 5.5$ \\
\hline Men, n (\%) & $13(59.1)$ & $4(40)$ & $71(62.3)$ & $352(57.5)$ & $126(69.6)$ & $72(69.2)$ \\
\hline Mean BMl, kg/m2 (SD) & $31.0 \pm 2.8$ & $31.8 \pm 4.9$ & $31.3 \pm 4.5$ & $31.1 \pm 4.4$ & $31.4 \pm 4.8$ & $31.6 \pm 4.7$ \\
\hline Smoking history, n (\%) & $18(85.7)$ & $8(80)$ & $86(75.4)$ & $451(73.8)$ & $141(78.3)$ & $86(82.7)$ \\
\hline HTN (Yes), n (\%) & $10(45.5)$ & $8(80)$ & $53(46.5)$ & $255(41.7)$ & $88(48.6)$ & $46(44.7)$ \\
\hline Diabetes (Yes), n (\%) & $7(31.8)$ & $6(60)$ & $39(34.2)$ & $224(37)$ & $66(36.9)$ & $24(23.5)$ \\
\hline CVD (yes), n (\%) & $3(13.6)$ & $5(50)$ & $37(32.7)$ & $119(19.5)$ & $77(43)$ & $39(38.2)$ \\
\hline
\end{tabular}

$B M I$ denotes body mass index, CVD cardiovascular diseases, HTN hypertension

Age and $\mathrm{BMI}$ are presented as mean \pm standard deviation (SD)

except fibrinogen, which was higher in the statin groups (Table 2). The difference was most notable in FXI:C, which showed almost $17 \mathrm{IU} / \mathrm{dL}$ lower levels in statin users than fibrate/niacin users (mean difference-17.1 $\mathrm{IU} / \mathrm{dL}, 95 \% \mathrm{CI})-30.0$ to -4.3$)$. Adjustment for potential confounding factors did not change the results (mean difference $-18.3 \mathrm{IU} / \mathrm{dL}$, 95\% CI -27.3 to -9.4 ). Additionally, current statin users had lower FIX and FVIII (adjusted mean difference - $11.3 \mathrm{IU} / \mathrm{dL}, 95 \% \mathrm{CI}-23.2$ to 0.4 ), and $-15.8 \mathrm{IU} / \mathrm{dL}, 95 \% \mathrm{CI}-31.6$ to 0.003 , respectively) with borderline statistical significance. Rosuvastatin users appeared to have lower levels of FVIII and
FIX, than users of other types of statins, though these analyses were hampered by small numbers (Table 3 ).

\section{Discussion}

We found that current users of statins had lower plasma levels of FXI:C than fibrate/niacin users. The results of our study confirm findings of the STAtins Reduce Thrombophilia (START) trial, which concluded that onemonth treatment with rosuvastatin $20 \mathrm{mg}$ daily in patients with prior VTE reduced the plasma levels of coagulation factors VII:C, FVIII:C, FXI:C and von Willebrand factor (vWF):Ag in comparison with non-statin users [17]. We

Table 2 Mean difference of coagulation factors among different lipid-lowering drugs users

\begin{tabular}{|c|c|c|c|}
\hline & Mean level & Mean difference $(95 \% \mathrm{Cl})$ & Adjusted mean difference ${ }^{a}(95 \% \mathrm{Cl})$ \\
\hline \multicolumn{4}{|l|}{ Fibrinogen, $\mathrm{mg} / \mathrm{dL}$} \\
\hline Fibrate/Niacin users $(n=21)$ & $294.4 \pm 52.5$ & Reference & Reference \\
\hline All statin users $(n=1007)$ & $316.1 \pm 68.4$ & $21.6(-7.8$ to 51.1$)$ & $19.1(-10.0$ to 48.2$)$ \\
\hline Rosuvastatin users $(n=104)$ & $316.3 \pm 54.0$ & $21.8(-3.6$ to 47.3$)$ & 20.7 (-6.2 to 47.6) \\
\hline Other statin users ( $n=903)$ & $316.0 \pm 69.9$ & $21.6(-8.5$ to 51.7$)$ & $18.6(-11.0$ to 48.4$)$ \\
\hline \multicolumn{4}{|l|}{$F V I I I, I U / d L$} \\
\hline Fibrate/Niacin users $(n=21)$ & $142.1 \pm 34.4$ & Reference & Reference \\
\hline All statin users $(n=1008)$ & $130.5 \pm 36.5$ & $-11.5(-27.3$ to 4.2$)$ & -15.8 ( -31.6 to 0.003$)$ \\
\hline Rosuvastatin users $(n=104)$ & $127.2 \pm 33.1$ & $-14.8(-30.6$ to 0.9$)$ & $-17.6(-33.8$ to -1.3$)$ \\
\hline Other statin users $(n=904)$ & $130.9 \pm 36.6$ & $-11.5(-27.1$ to 4.7$)$ & $-15.5(-31.5$ to 0.5$)$ \\
\hline \multicolumn{4}{|l|}{$F I X, I U / d L$} \\
\hline Fibrate/Niacin users $(n=21)$ & $136.5 \pm 29.2$ & Reference & Reference \\
\hline All statin users $(n=1008)$ & $125.2 \pm 27.6$ & $-11.2(-23.2$ to 0.7$)$ & $-11.3(-23.2$ to 0.4$)$ \\
\hline Rosuvastatin users ( $n=104)$ & $122.4 \pm 30.5$ & -14.1 ( -28.4 to 0.2$)$ & $-14.9(-29.7$ to -0.08$)$ \\
\hline Other statin users $(n=904)$ & $125.6 \pm 27.3$ & $-10.9(-22.7$ to 0.9$)$ & $-11.0(-22.7$ to 0.7$)$ \\
\hline \multicolumn{4}{|l|}{$F X I, I U / d L$} \\
\hline Fibrate/Niacin users $(n=21)$ & $137.6 \pm 28.0$ & Reference & Reference \\
\hline All statin users $(n=1008)$ & $120.4 \pm 20.9$ & $-17.1(-30.0$ to -4.3$)$ & $-18.3(-27.3$ to -9.4$)$ \\
\hline Rosuvastatin users $(n=104)$ & $120.4 \pm 18.4$ & $-17.2(-26.8$ to -7.5$)$ & $-17.6(-27.4$ to -7.7$)$ \\
\hline Other statin users $(n=904)$ & $120.4 \pm 21.2$ & $-17.1(-26.4$ to -7.9$)$ & $-18.3(-27.4$ to -9.2$)$ \\
\hline
\end{tabular}


Table 3 Comparative results of mean difference in coagulation profile among individuals using different lipid-lowering drugs

\begin{tabular}{|c|c|c|c|}
\hline & Adjusted mean difference ${ }^{a}(95 \% \mathrm{Cl})$ & Adjusted mean difference ${ }^{a}(95 \% \mathrm{Cl})$ & Adjusted mean difference ${ }^{a}(95 \% \mathrm{Cl})$ \\
\hline \multicolumn{4}{|l|}{ Fibrinogen, $\mathrm{mg} / \mathrm{dL}$} \\
\hline Fibrate/Niacin users & - & Reference & Reference \\
\hline Other statin users & Reference & - & $18.6(-11.0$ to 48.4$)$ \\
\hline Rosuvastatin users & $1.5(-12.1$ to 15.3$)$ & - & $20.7(-6.2$ to 47.6$)$ \\
\hline All statin users & - & $19.1(-10.0$ to 48.2$)$ & - \\
\hline \multicolumn{4}{|l|}{ Factor VIII, IU/dL } \\
\hline Fibrate/Niacin users & - & Reference & Reference \\
\hline Other statin users & Reference & - & $-15.5(-31.5$ to 0.5$)$ \\
\hline Rosuvastatin users & $-2.6(-10.1$ to 4.7$)$ & - & $-17.6(-33.8$ to -1.3$)$ \\
\hline All statin users & - & -15.8 ( -31.6 to 0.003$)$ & - \\
\hline \multicolumn{4}{|l|}{ Factor IX, IU/dL } \\
\hline Fibrate/Niacin users & - & Reference & Reference \\
\hline Other statin users & Reference & - & $-11.0(-22.7$ to 0.7$)$ \\
\hline Rosuvastatin users & $-2.3(-7.9$ to 3.1$)$ & - & $-14.9(-29.7$ to -0.08$)$ \\
\hline All statin users & - & $-11.3(-23.2$ to 0.4$)$ & - \\
\hline \multicolumn{4}{|l|}{ Factor XI, IU/dL } \\
\hline Fibrate/Niacin users & - & Reference & Reference \\
\hline Other statin users & Reference & - & $-18.3(-27.4$ to -9.2$)$ \\
\hline Rosuvastatin users & $0.3(-3.8$ to 4.5$)$ & - & $-17.6(-27.4$ to -7.7$)$ \\
\hline All statin users & - & $-18.3(-27.3$ to -9.4$)$ & - \\
\hline
\end{tabular}

Cl confidence interval

adjusted for age, sex, body mass index, hypertension, smoking, diabetes, cardiovascular diseases

also showed that current statin users had $18.3 \mathrm{IU} / \mathrm{dL}$ (9.4 to 27.3) lower FXI:C and $15.8 \mathrm{IU} / \mathrm{dL}(-0.003$ to 31.6$)$ lower FVIII:C than individuals who used fibrates/niacin as their lipid-lowering drugs. The observed difference seems to be mostly related to rosuvastatin use than other types of statins as they consistently showed almost $18 \mathrm{IU} / \mathrm{dL}$ lower levels of FVIII:C and FXI:C and about 15 IU/dL less FIX:C compared to non-statin users (Table 3 ).

The effects of statins on coagulation factor levels were previously noted in different studies. In the Multi-Ethnic Study of Atherosclerosis (MESA) cohort consisting of people free of cardiovascular disease or active cancer, statin users had lower adjusted D-dimer and FVIII levels than non-statin users [14]. Treatment with simvastatin in patients with impaired glucose tolerance and hypercholesterolemia reduced plasma levels of fibrinogen, FX: C, vWF:Ag, PAI-1, and FVII activity. It also led to prolongation of the prothrombin time and activated partial thromboplastin time. Co-administration of ezetimibe with simvastatin showed a synergistic effect on the coagulation profile [24, 25]. Additionally, it was reported that ezetimibe might increase and stabilize the anticoagulant effects of warfarin, particularly when added to statins [26]. Similarly, rosuvastatin but not pitavastatin increased the international normalized ratio (INR) in healthy volunteers on steady-state warfarin [27]. A
Dutch study that assessed the immediate and long-term effects of new statin use on the dosage of vitamin $\mathrm{K}$ antagonist (VKA) showed that statin users needed lower doses of VKA to achieve the target INR, with the most substantial effect seen with simvastatin and rosuvastatin [28]. Pravastatin was also noted to potentiate the anticoagulant effects of dalteparin [29].

On the other hand, co-administration of rosuvastatin and warfarin in a small number of healthy subjects did not affect warfarin's steady-state pharmacodynamics [30]. It was also reported that rosuvastatin did not inhibit thromboxane-mediated platelet aggregation in patients with a previous history of VTE [31]. Moreover, one-year treatment with atorvastatin or simvastatin in patients with coronary heart disease had no significant effect on the measured coagulation variables, though they were accompanied by an improved fibrinolytic profile in the treated patients [32]. There have also been reports suggesting that statins do not affect FVII and FVIII levels or activity [33-37].

While the observed differences in coagulation profile, particularly FVIII and FIX, between statin-users and fibrate/niacin-users in our study cohort, were seemingly more attributed to rosuvastatin, we could not detect a difference between rosuvastatin and other types of statin probably because of small numbers. It is believed that 
the side effects of drugs are not necessarily class effects, especially when the primary mechanism of the drug and the mechanism of side effects are different [38]. Therefore, it makes sense to expect that statins' antithrombotic properties may be limited to some statins. In most observational studies and randomized controlled trials, it was concluded that rosuvastatin use was associated with the strongest (nearly $40 \%$ ) reduced risk of VTE compared to non-statin users [20, 39-42]. Furthermore, in a Dutch cohort of patients with prior history of pulmonary emboli (PE), highly potent statins with regards to lipid-lowering effects (e.g., rosuvastatin) had the most substantial effect in preventing PE recurrence (hazard ratio (HR) $0.29,95 \%$ CI $0.07-1.16$ ) followed by statins of moderate potency (e.g., atorvastatin; HR 0.44, 95\% CI $0.3-0.65$ ) and low potency (e.g., pravastatin; HR 0.88, 95\% CI 0.5-1.54) [43]. Despite these findings, several reports emphasize no difference between the type of statin and the risk of first or recurrent VTE [7, 44, 45].

Finally, we showed that contrary to other measured coagulation factors, fibrinogen level was higher in statin users than fibrate/niacin users, though the difference was statistically insignificant. Since fibrinogen is associated with pro-inflammatory and pro-coagulants effects [46], one would expect that statins will decrease fibrinogen levels. A previous study reported that the fibrinogen level reduced after 12 weeks of treatment with simvastatin $20 \mathrm{mg}$ daily in individuals with impaired fasting glucose and hypercholesterolemia [24]. However, in a meta-analysis of 14 other studies, including patients with high serum cholesterol or stable coronary disease, no effect of statins on fibrinogen was found [47]. In a population-based study with 1000 statin users, fibrinogen levels were significantly higher in statin users than in non-users after adjusting for cardiovascular risk factors $[14,47]$. We recently confirmed in the START randomized trial [17] that rosuvastatin users had higher fibrinogen levels than non-statin users [48]. It is presently unknown why statins can increase fibrinogen levels, but the timing of plasma fibrinogen level measurement and the type of statin used in different studies may explain such variability.

Our study was conducted with an active comparator design to minimize potential confounding and help us to make treatment groups with similar treatment indications. We compared different statin users with fibrates/ niacin users as the reference group. Such a study design was previously explored in the control subjects of the Multiple Environmental and Genetic Assessment of risk factors for venous thrombosis (MEGA) study, which showed statin users had a less hypercoagulable profile than fibrate users. Among the studied statins, rosuvastatin users had the lowest levels of FII, FVII, FVIII, vWF: Ag, FIX, FX, and FXI [38]. However, the latter study was conducted with a small number of participants $(n=361)$, which made the authors warn that the finding should be interpreted cautiously [30]. Therefore, we included a much larger population $(n=1043)$ to overcome this shortcoming and mainly found similar results in MEGA.

Besides, in a cohort of Japanese subjects who were LDL-cholesterol matched at baseline and were treated either with statins or fibrates, the overall mean LDL cholesterol level was lower by $27.3 \mathrm{mg} / \mathrm{dl}$ in statin users than in fibrate users $(P<0.001)$ [49]. Furthermore, a meta-analysis of fourteen studies revealed that statin use significantly reduced VTE risk (OR, 0.81; 95\% CI, 0.66 0.99 , random-effect model), while the use of fibrates was associated with a significant increase in the risk of VTE (OR, 1.58; 95\% CI, 1.23-2.02), and niacin did not change the risk of VTE [50]. Thus, it seems that statins are more potent drugs than fibrates in lowering LDL-cholesterol, reducing the risk of atherosclerosis, and reducing coagulation factors, which may ultimately lead to a lower risk of first or recurrent VTE.

Our study was limited by the small numbers of niacin/ fibrate users as the reference group. Though we used an active comparator design to minimize confounding, residual confounding might have remained since those prescribed fibrates/niacin may differ from those who received a statin prescription. Besides, we cannot exclude the possibility of adherence bias affecting our results since we included prevalent statins users. Additionally, since the analyses were cross-sectional, causal inferences cannot be made. Setting up a randomized controlled trial is advised to attenuate the possibility of adherence bias, and it is comforting to see that our results are in line with findings from the START trial.

\section{Conclusion}

Current statin use is associated with lower plasma levels of FXI. The type of statin may matter, though it needs further randomized control trials with much larger sample sizes.

\section{Abbreviations}

VTE: Venous thromboembolism; F: Factor; BMI: Body mass index; Cl: Confidence interval; tPA: Tissue plasminogen activator; NEO: The Netherlands Epidemiology of Obesity; ESC: The European Society of Cardiology; EAS: The European Atherosclerosis Society; BP: Blood pressure; START: STAtins Reduce Thrombophilia; VWF: Von Willebrand factor; MESA: Multi-Ethnic Study of Atherosclerosis; INR: International normalized ratio; VKA: Vitamin K antagonist; PE: Pulmonary emboli; HR: Hazard ratio; MEGA: The Multiple Environmental and Genetic Assessment of risk factors for venous thrombosis

\section{Acknowledgments}

We acknowledge S. Parand for her kind help in preparing and submitting the manuscript

\section{Authors' contributions}

FRR and WML have contributed to the concept and design of the study. MB and $M C$ gathered the data. $M B, M C$, and $W M L$ performed statistical analysis. RM, JWJ, FRR, and WML interpreted the data. MB wrote the initial draft. All 
the authors reviewed the drafts, provided critical comments, and approved the final manuscript.

\section{Funding}

None.

\section{Availability of data and materials}

The data used during the current study are available from the corresponding author on reasonable request.

\section{Declarations}

\section{Ethics approval and consent to participate}

The study was approved by the medical ethical committee of the Leiden University Medical Center (LUMC). Participants have given written informed consent for participation in the study and obtained medical records and information on vital status during follow-up. They also gave consent that the data can be used for research purposes.

\section{Consent for publication}

Not applicable.

\section{Competing interests}

The authors have no competing interests.

\section{Author details}

${ }^{1}$ Hematology Research Center, Shiraz University of Medical Sciences, Shiraz, Iran. ${ }^{2}$ Department of Clinical Epidemiology, Leiden University Medical Center, Albinusdreef 2, 2333, ZA, Leiden, The Netherlands. ${ }^{3}$ Department of Cardiology, Leiden University Medical Centre, Leiden, the Netherlands.

\section{Received: 22 March 2021 Accepted: 9 June 2021}

\section{Published online: 27 June 2021}

\section{References}

1. Heit JA, Spencer FA, White RH. The epidemiology of venous thromboembolism. J Thromb Thrombolysis. 2016:41(1):3-14.

2. Pastori D, Farcomeni A, Milanese A, Del Sole F, Menichelli D, Hiatt WR, et al. Statins and major adverse limb events in patients with peripheral artery disease: a systematic review and meta-analysis. Thromb Haemost. 2020; 120(5):866-75

3. Braekkan SK, Caram-Deelder C, Siegerink B, van Hylckama VA, le Cessie S, Rosendaal FR, et al. Statin use and risk of recurrent venous thrombosis: results from the MEGA follow-up study. Res Pract Thromb Haemostasis. 2017;1 (1):112-9.

4. Kunutsor SK, Seidu S, Khunti K. Statins and secondary prevention of venous thromboembolism: pooled analysis of published observational cohort studies. Eur Heart J. 2017;38(20):1608-12.

5. Li L, Zhang P, Tian JH, Yang K. Statins for primary prevention of venous thromboembolism. Cochrane Database Syst Rev. 2014;12:Cd008203.

6. Schmidt M, Cannegieter SC, Johannesdottir SA, Dekkers OM, Horvath-Puho E, Sorensen HT. Statin use and venous thromboembolism recurrence: a combined nationwide cohort and nested case-control study. J Thromb Haemostasis. 2014;12(8):1207-15.

7. Smith NL, Harrington LB, Blondon M, Wiggins KL, Floyd JS, Sitlani CM, et al. The association of statin therapy with the risk of recurrent venous thrombosis. J Thromb Haemostasis. 2016:14(7):1384-92.

8. Tagalakis V, Eberg M, Kahn S, Azoulay L. Use of statins and reduced risk of recurrence of VTE in an older population. A population-based cohort study. Thromb Haemost. 2016;115(6):1220-8.

9. Lassila R, Jula A, Pitkaniemi J, Haukka J. The association of statin use with reduced incidence of venous thromboembolism: a population-based cohort study. BMJ Open. 2014;4(11):e005862.

10. Gaertner S, Cordeanu EM, Nouri S, Mirea C, Stephan D. Statins and prevention of venous thromboembolism: myth or reality? Arch Cardiovasc Dis. 2016;109(3):216-22

11. Takemoto M, Liao JK. Pleiotropic effects of 3-hydroxy-3-methylglutaryl coenzyme a reductase inhibitors. Arterioscler Thromb Vasc Biol. 2001;21(11): $1712-9$
12. Pignatelli $P$, Carnevale R, Pastori D, Cangemi R, Napoleone L, Bartimoccia $S$, et al. Immediate antioxidant and antiplatelet effect of atorvastatin via inhibition of Nox2. Circulation. 2012;126(1):92-103.

13. Chaffey P, Thompson M, Pai AD, Tafreshi AR, Tafreshi J, Pai RG. Usefulness of statins for prevention of venous thromboembolism. Am J Cardiol. 2018; 121(11):1436-40.

14. Adams NB, Lutsey PL, Folsom AR, Herrington DH, Sibley CT, Zakai NA, et al. Statin therapy and levels of hemostatic factors in a healthy population: the multi-ethnic study of atherosclerosis. J Thromb Haemostasis. 2013;11(6): 1078-84.

15. Bianconi V, Sahebkar A, Banach M, Pirro M. Statins, haemostatic factors and thrombotic risk. Curr Opin Cardiol. 2017;32(4):460-6.

16. Oikonomou E, Leopoulou M, Theofilis P, Antonopoulos AS, Siasos G, Latsios $G$, et al. A link between inflammation and thrombosis in atherosclerotic cardiovascular diseases: clinical and therapeutic implications. Atherosclerosis. 2020;309:16-26

17. Biedermann JS, Kruip M, van der Meer FJ, Rosendaal FR, Leebeek FWG, Cannegieter SC, et al. Rosuvastatin use improves measures of coagulation in patients with venous thrombosis. Eur Heart J. 2018:39(19):1740-7.

18. Law MR, Wald NJ, Rudnicka AR. Quantifying effect of statins on low density lipoprotein cholesterol, ischaemic heart disease, and stroke: systematic review and meta-analysis. BMJ (Clinical research ed). 2003;326(7404):1423.

19. Sipahi I, Nicholls SJ, Tuzcu EM, Nissen SE. Coronary atherosclerosis can regress with very intensive statin therapy. Cleve Clin J Med. 2006;73(10): 937-44.

20. Rahimi K, Bhala N, Kamphuisen P, Emberson J, Biere-Rafi S, Krane V, et al Effect of statins on venous thromboembolic events: a meta-analysis of published and unpublished evidence from randomised controlled trials. PLoS Med. 2012;9(9):e1001310.

21. de Mutsert R, den Heijer M, Rabelink TJ, Smit JW, Romijn JA, Jukema JW et al. The Netherlands epidemiology of obesity (NEO) study: study design and data collection. Eur J Epidemiol. 2013:28(6):513-23.

22. Reiner Z, Catapano AL, De Backer G, Graham I, Taskinen MR, Wiklund O, et al. ESC/EAS guidelines for the management of dyslipidaemias: the task force for the management of dyslipidaemias of the European Society of Cardiology (ESC) and the European atherosclerosis society (EAS). Eur Heart J. 2011;32(14):1769-818.

23. Ramcharan AS, Van Stralen KJ, Snoep JD, Mantel-Teeuwisse AK, Rosendaal FR, Doggen CJ. HMG-CoA reductase inhibitors, other lipid-lowering medication, antiplatelet therapy, and the risk of venous thrombosis. J Thromb Haemostasis. 2009:7(4):514-20.

24. Krysiak R, Okopien B. Haemostatic effects of simvastatin in subjects with impaired glucose tolerance. Intern Med J. 2011;41(6):473-81.

25. Krysiak R, Zmuda W, Okopien B. The effect of ezetimibe and simvastatin on hemostasis in patients with isolated hypercholesterolemia. Fundam Clin Pharmacol. 2012;26(3):424-31.

26. Hashikata T, Yamaoka-Tojo M, Kakizaki R, Nemoto T, Fujiyoshi K, Namba S, et al. Ezetimibe enhances and stabilizes anticoagulant effect of warfarin. Heart Vessel. 2017;32(1):47-54.

27. Yu CY, Campbell SE, Zhu B, Knadler MP, Small DS, Sponseller CA, et al. Effect of pitavastatin vs. rosuvastatin on international normalized ratio in healthy volunteers on steady-state warfarin. Curr Med Res Opin. 2012;28(2):187-94.

28. van Rein N, Biedermann JS, Bonafacio SM, Kruip MJ, van der Meer FJ, Lijfering WM. Statin use decreases coagulation in users of vitamin K antagonists. Eur J Clin Pharmacol. 2016;72(12):1441-7.

29. Zimmer JE, Spillert CR, Puppala S, Zamecki K, Bhatt BA, Arora RR. Pravastatin potentiates the anticoagulant effects of low molecular weight heparin. Thromb Res. 2004;113(6):407-10.

30. Jindal D, Tandon M, Sharma S, Pillai KK. Pharmacodynamic evaluation of warfarin and rosuvastatin co-administration in healthy subjects. Eur J Clin Pharmacol. 2005:61(9):621-5.

31. Biedermann JS, Cannegieter SC, Roest M, van der Meer FJ, Reitsma PH, Kruip MJ, et al. Platelet reactivity in patients with venous thrombosis who use rosuvastatin: a randomized controlled clinical trial. J Thromb Haemostasis. 2016;14(7):1404-9.

32. Seljeflot I, Tonstad S, Hjermann I, Arnesen H. Improved fibrinolysis after 1year treatment with HMG CoA reductase inhibitors in patients with coronary heart disease. Thromb Res. 2002;105(4):285-90.

33. Joukhadar C, Klein N, Prinz M, Schrolnberger C, Vukovich T, Wolzt M, et al. Similar effects of atorvastatin, simvastatin and pravastatin on thrombogenic 
and inflammatory parameters in patients with hypercholesterolemia. Thromb Haemost. 2001;85(1):47-51.

34. Dangas G, Badimon JJ, Smith DA, Unger AH, Levine D, Shao JH, et al. Pravastatin therapy in hyperlipidemia: effects on thrombus formation and the systemic hemostatic profile. J Am Coll Cardiol. 1999;33(5):1294-304.

35. Gottsater A, Anwaar I, Lind P, Mattiasson I, Lindgarde F. Increasing plasma fibrinogen, but unchanged levels of intraplatelet cyclic nucleotides, plasma endothelin-1, factor VII, and neopterin during cholesterol lowering with fluvastatin. Blood Coagul Fibrinolysis. 1999;10(3):133-40.

36. Sbarouni E, Melissari E, Kyriakides ZS, Kremastinos DT. Effects of simvastatin or hormone replacement therapy, or both, on fibrinogen, factor VII, and plasminogen activator inhibitor levels in postmenopausal women with proven coronary artery disease. Am J Cardiol. 2000;86(1):80-3.

37. Ambrosi P, Aillaud MF, Habib G, Kreitmann B, Metras D, Luccioni R, et al. Fluvastatin decreases soluble thrombomodulin in cardiac transplant recipients. Thromb Haemost. 2000;83(1):46-8.

38. Lijfering WM, Biedermann JS, Kruip MJ, Leebeek FW, Rosendaal FR, Cannegieter SC. Can we prevent venous thrombosis with statins: an epidemiologic review into mechanism and clinical utility. Expert Rev Hematol. 2016;9(11):1023-30.

39. Kunutsor SK, Seidu S, Khunti K. Statins and primary prevention of venous thromboembolism: a systematic review and meta-analysis. Lancet Haematol. 2017:4(2):e83-93

40. Glynn RJ, Danielson E, Fonseca FA, Genest J, Gotto AM Jr, Kastelein JJ, et al. A randomized trial of rosuvastatin in the prevention of venous thromboembolism. N Engl J Med. 2009:360(18):1851-61.

41. Hippisley-Cox J, Coupland C. Unintended effects of statins in men and women in England and Wales: population based cohort study using the QResearch database. BMJ (Clinical research ed). 2010;340:c2197.

42. Rosendaal FR. Statins and venous thrombosis: a story too good to be true? PLoS Med. 2012;9(9):e1001311.

43. Biere-Rafi S, Hutten BA, Squizzato A, Ageno W, Souverein PC, de Boer A, et al. Statin treatment and the risk of recurrent pulmonary embolism. Eur Heart J. 2013;34(24):1800-6

44. Agarwal V, Phung OJ, Tongbram V, Bhardwaj A, Coleman Cl. Statin use and the prevention of venous thromboembolism: a meta-analysis. Int J Clin Pract. 2010:64(10):1375-83.

45. El-Refai SM, Black EP, Adams VR, Talbert JC, Brown JD. Statin use and venous thromboembolism in cancer: a large, active comparator, propensity score matched cohort study. Thromb Res. 2017;158:49-58.

46. Davalos D, Akassoglou K. Fibrinogen as a key regulator of inflammation in disease. Seminars in immunopathology; 2012.

47. Balk EM, Lau J, Goudas LC, Jordan HS, Kupelnick B, Kim LU, et al. Effects of statins on nonlipid serum markers associated with cardiovascular disease: a systematic review. Ann Intern Med. 2003;139(8):670-82.

48. Schol-Gelok S, de Maat MPM, Biedermann JS, van Gelder T, Leebeek FWG, Lijfering WM, et al. Rosuvastatin use increases plasma fibrinolytic potential: a randomised clinical trial. Br J Haematol. 2020;190:916

49. Takeuchi S, Takahashi Y, Asai S. Comparison of pleiotropic effects of statins vs fibrates on laboratory parameters in patients with dyslipidemia: a retrospective cohort study. Medicine. 2020;99(50):e23427.

50. Squizzato A, Galli M, Romualdi E, Dentali F, Kamphuisen PW, Guasti L, et al. Statins, fibrates, and venous thromboembolism: a meta-analysis. Eur Heart J. 2010;31(10):1248-56.

\section{Publisher's Note}

Springer Nature remains neutral with regard to jurisdictional claims in published maps and institutional affiliations.

Ready to submit your research? Choose BMC and benefit from:
- fast, convenient online submission
- thorough peer review by experienced researchers in your field
- rapid publication on acceptance
- support for research data, including large and complex data types
- gold Open Access which fosters wider collaboration and increased citations
- maximum visibility for your research: over 100M website views per year
At BMC, research is always in progress.
Learn more biomedcentral.com/submissions

